\title{
PUSAT INTEGRASI AGRIKULTUR DI BUMI SERPONG DAMAI
}

\author{
Yunior Dharma Aryindra ${ }^{1)}$, Petrus Rudi Kasimun ${ }^{2)}$ \\ 1)Program Studi S1 Arsitektur, Fakultas Teknik, Universitas Tarumanagara, ydharmaaryindra@gmail.com \\ ${ }^{2)}$ Program Studi S1 Arsitektur, Fakultas Teknik, Universitas Tarumanagara, rudi.kasimun@gmail.com
}

\begin{abstract}
Abstrak
Pemerintah memiliki gagasan untuk mengembangkan Kawasan Pertanian Modern di BSD (Bumi Serpong Damai) seluas $36 \mathrm{Ha}$ yang dapat memberikan dukungan terhadap lahan pertanian seluas $700 \mathrm{Ha}$ di sekitar kawasan tersebut. Oleh karena itu, dibutuhkan wadah produsen kota. Pusat Integrasi Agrikultur memiliki potensi dirancang untuk mengurangi hambatan antara konsumen dan produsen yang biasanya berlangsung secara berjenjang dan panjang namun dengan adanya pusat ini dapat memutuskan rantai tersebut sehingga dapat menciptakan iklim yang berkelanjutan dan efisien. Serta dengan letaknya yang berada di tengah kota memberikan edukasi secara langsung bagi masyarakat kota mengenai apa itu pertanian serta pembaharuan dan pengembangan teknologi-teknologi pertanian. Pusat Integrasi Agrikultur di Bumi Serpong Damai beroperasi dengan beberapa program utama yang sifatnya melayani dan menyediakan semua tahapan proses produksi pangan hingga sampai ke tangan konsumen. Dimulai dari produksi, proses, memasak hingga penjualan tersedia disini ditambah dengan adanya fasilitas riset dan kantor bagi start-up muda yang ingin masuk ke dalam dunia agrikultur juga tersedia di sini. Dengan lokasi yang berada di kawasan CBD (Central Business District) BSD serta berbatasan langsung dengan lahan pertanian menjadikan Pusat Integrasi Agrikultur sebagai konektor antara kawasan perkotaan dan lahan pertanian, yang tidak memutus tetapi menyambungkan antar keduanya.
\end{abstract}

Kata kunci: Agrikultur; berkelanjutan; kota; siklus

\begin{abstract}
The government has the idea to develop a Modern Agricultural Zone in BSD (Bumi Serpong Damai) covering an area of 36ha which can support for 700ha of agricultural land around the area. We need a place where producers, consumers and the public can gather together to explore, develop and share experiences in the food production system in urban area. This will be great first movement for the next greater movement so that agriculture can merge into city-life and become a daily life for the urban community. Agricultural Hub in BSD has potentiallity to reduce barriers between consumers and producers which usually take long times cyclus because production activies are carried in the villages and sales in urban areas, but with this Agricultral Hub we can break the long chain so it can create a sustainable and efficient cyclus. Because this building located in the middle of the city, it provides direct education for the urban community about agriculture and the renewal and development of agricultural technologies. Agricultural Hub in Bumi Serpong Damai operates with a number of main programs whose serving and providing all cyclus of the food production process to reach consumers. Starting from production, process, cooking to sales available in here, plus there are research facilities and offices for young start-ups who want to enter the world of agriculture. Located in the CBD (Central Business District) of BSD and directly adjacent to agricultural land makes Agricultural Hub in Bumi Serpong Damai a connector between urban areas and agricultural land, which make benefit to the areas.
\end{abstract}

Keywords: Agriculture; cyclus; sustainable; urban

\section{PENDAHULUAN}

Urbanisasi yang didominasi oleh usia muda semakin meningkat dari tahun ke tahun, menyebabkan tenaga kerja di pedesaan sebagai penghasil pangan menjadi berkurang. Apabila hal ini tidak ditanggulangi maka dunia akan mengalami kekurangan pangan. Dengan perkembangan teknologi dan loT (Internet of Things) membuat kita dapat mengakses informasi dimanapun dan dikapanpun, sehingga terbentuklah generasi baru yang terpengaruh 
oleh hal ini dengan nama Generasi milenial atau Generasi $Y$, yang kini merupakan generasi dengan usia produktif juga bertindak sebagai produsen dan juga konsumen dalam dunia agrikultur. Generasi ini tentu berbeda dengan generasi sebelumnya, generasi ini menginginkan suatu yang lebih cepat serta efisien dan saling berbagi terhadap satu sama lainnya.

Pemerintah Kota Tangerang mencatat saat ini terdapat sekitar 500 hektar lahan pertanian yang tersebar di Kota Tangerang, dan terdapat kurang lebih 200 ha lahan pertanian di Kota Tangerang Selatan, serta rencana pemerintah untuk membangun kawasan pertanian modern di Serpong seluas $36 \mathrm{Ha}$. Menjadikan BSD (Bumi Serpong Damai) sebagai induk kawasan pertanian modern di area Tangerang, rencana ini perlu didukung dengan program yang dapat menciptakan siklus pertanian secara berkelanjutan di kawasan tersebut.

Terdapat siklus yang panjang dalam proses produksi pangan secara konvensional oleh karena itu perlu adanya bangunan dengan berbagai program untuk memutus rantai tersebut sehingga semua tahapan proses produksi pangan hingga sampai ke tangan konsumen terjadi di sebuah tempat, sesuai dengan kebutuhan saat ini dimana generasi millennial menginginkan sesuatu yang instan dan dapat merasakan sensasi langsung pengalaman proses produksi pangan. Oleh karena itu dibutuhkan program yang dapat mendukung kegiatan tersebut antara lain produksi, processing, edukasi, dan komersil yang dihubungkan di dalam Pusat Integrasi Agrikultur di BSD yang mampu menjadi meningkatkan nilai kawasan dan menjadi jembatan antara kawasan urban dan kawasan pertanian di lingkungan tersebut.

Dengan adanya Pusat Integrasi Agrikultur diharapkan dapat mampu menjawab kebutuhan generasi milenial dengan lebih cepat dan efisien guna menciptakan iklim yang berkelanjutan dan memutus rantai panjang dari pertanian konvensional agar dapat memberikan keuntungan bagi semua pihak, serta memberi wajah baru juga nilai positif bagi kawasan tersebut dan mampu mewadahi, menjadi tempat bertemunya kebutuhan dari orang-orang yang terlibat dalam proses produksi hingga penjualan.

\section{KAJIAN LITERATUR}

Sumber utama kepustakaan diperoleh dari sumber buku, jurnal, dan indeks-indeks lainnya. Untuk membahas generasi millennial dan karakteristiknya menggunakan sumber utama yaitu "Millennial Behaviors \& Demographics" karangan Richard Sweeney, lalu untuk membahas mengenai pertanian dan kondisinya di Indonesia mengacu pada berbagai buku, jurnal dan sumber berita.

Setiap generasi pada zamannya mempunyai ciri dan karakteristik masing-masing. Beragam kesamaan ataupun perbedaan di dalamnya layaknya dapat dijadikan sebagai gambaran umum. Generasi millennial/ Gen Y yang lahir dari tahun 1980-2000 (Sweeney R, 2006) memiliki karakteristik yang berbeda dari generasi lainnya, diantaranya adalah:

a. Mempunyai preferensi yang spesifik.

b. Belajar dari pengalaman dan menyukai eksplorasi.

c. Mempunyai tingkat fleksibilitas yang lebih tinggi.

d. Menyukai personalisasi dan kostumisasi.

e. Menginginkan sesuatu secara cepat/ instant,

f. Praktikal dan berorientasi pada hasil.

g. Multitasker.

h. Digital Natives.

i. Gamers

j. Nomadic Communication Style

k. Media/ Format Agnostic

I. Menyukai kolaborasi.

m. Menyeimbangkan hidup.

n. Lebih sedikit membaca. 
Pertanian adalah kegiatan yang dilakukan manusia untuk memperoleh bahan pangan dengan cara memanfaatkan sumber daya hayati yang ada demi memenuhi kebutuhan hidup. Banyak hal yang membedakan antara pertanian kini dan dulu; (J.B. Penn, 2016) mengatakan pada awal tahun 1900an pertanian masih menggungkan kekuatan hewan, namun mesin kemudian mulai menggantikan hewan tersebut dalam pertanian. Hingga munculnya rekayasa genetik untuk membuat bibit unggul hingga penggunaan bahan kimia dan pestisida yang mempercepat pertumbuhan tanaman namun untuk jangka panjang merusak lingkungan dan membahayakan kesehatan manusia. Kini pada jaman sekarang dikenal dengan namanya IoT (Internet of Things), dunia pertanian juga ikut berubah, dengan adanya loT membuat pertanian menjadi lebih mudah dan sangat presisi serta akurat. Dengan pemanfaatan teknologi dan data membuat peningkatan produktifitas, kualitas produk dan pengembangan yang terkendali. Selain itu memberikan keuntungan kepada lingkungan yang berkelanjutan, dengan adanya data semuanya lebih efisien, efektif dan presisi. Sehingga dapat mengurangi polusi udara, mengurangi persebaran karbon serta mengurangi kemungkinan kerugian saat panen. Selain itu dengan produksi makanan yang lebih efisien, biaya produksi lebih rendah sehingga konsumen tidak perlu mengeluarkan uang yang besar untuk membeli pangan. Selain itu di jaman sekarang sesuai dengan tantangan dan arus urbanisasi ke kota, pertanian dapat didistribusikan dengan cepat. Melalui perdagangan yang diperluas ke global pangan akan lebih banyak tersalurkan sehingga menciptakan ketahanan pangan secara global. Selain itu dengan kehadiran petani di lingkungan urban, akan menambah penghasilan petani tersebut yang dulunya harus menjual ke tengkulak terlebih dahulu kini dapat langsung menyalurkan hasil taninya langsung ke konsumen, itu juga berlaku ke lingkungan lokal agar menciptakan stabilitas bagi lingkungan sekitar.

Pertanian berkelanjutan diciptakan untuk meningkatan kualitas kehidupan manusia. Dalam usaha mencapai tujuan tersebut, setidaknya ada tujuh macam kegiatan (Manguiat, 1995), yaitu: meningkatkan pembangunan ekonomi, memprioritaskan kecukupan pangan, meningkatkan harga diri, memberdayakan dan memerdekakan petani, menjaga stabilitas lingkungan (aman, bersih, seimbang, diperbarui), dan memfokuskan tujuan produktivitas untuk jangka panjang. Untuk mencapai tujuan tersebut, diperlukan pendekatan petanian berkelanjutan yang bersifat proaktif, berdasarkan pengalaman dan partisipatif. Dr. Soekarwati menyebutkan tiga alasan mengapa pembangunan pertanian di Indonesia harus berkelanjutan; Indonesia adalah negara agraris, sektor pertanian dalam sistem perekonomian nasional masih menjadi mayoritas. Kontribusinya terhadap PDB adalah sekitar 20\% (Dr. Soekarwati, 1995). Agrobisnis dan agroindustri memiliki peranan yang sangat vital dalam mendukung pembangunan sektor lainnya. Saat sektor industri dan perbankan mengalami krisis ekonomi, sektor agrobisnis dan agroindustri mengalami booming karena nilai tukar rupiah terhadap dolar AS melemah. Terakhir, sebagai negara agraris, pembangunan pertanian berkelanjutan harus menjadi keharusan agar sumber daya alam yang ada sekarang ini dapat terus dimanfaatkan untuk jangka waktu yang panjang. Karena sektor pertanian akan tetap menjadi tulang punggung untuk kelangsungan hidup Bangsa Indonesia. Jadi, Edukasi dan rekreasi pertanian adalah sarana untuk memberikan edukasi tentang pertanian dan rekreasi dengan memanfaatkan pertanian untuk masyarakat.

Dari uraian di atas kita mengetahui bahwa seiring dengan perkembangan zaman, maka akan melahirkan generasi dengan karakteristik yang berbeda dari generasi sebelumnya. Generasi milenial menginginkan sebuah percepatan dan efisiensi, dimana selama ini pertanian yang dijalankan secara konvensional harus melalui sebuah proses yang panjang dan tidak lagi sesuai dengan karakter dari generasi millennial. Oleh karena itu diperlukan desain yang dapat mewadahi kebutuhan yang sesuai dengan tuntutan perkembangan jaman.

\section{METODE}

Metode perancangan yang dilaksanakan pada perancangan ini yaitu programmatik (sistematis), dengan mempelajari terlebih dahulu perilaku Generasi milenial; serta studi-studi 
mengenai pertanian dan program bangunan berdasarkan studi literatur atau preseden, mempelajari Kawasan Edu-Town dan tapak yang berada di kawasan tersebut agar terbentuk program-program dan desain yang mampu memenuhi kebutuhan pengguna, serta dapat meningkatkan nilai kawasan.

\section{Strategi dalam Mendesain}

a. Menghadirkan program yang dapat menghubungkan lahan pertanian di kawasan tersebut dengan lingkungan perkotaan, sehingga menciptakan sebuah siklus pertanian yang berkelanjutan di kawasan tersebut.

b. Mencoba pendekatan yang berbeda dalam mengeksekusi sebuah fasilitas pendukung agrikultur yang lama menjadi sesuatu yang baru dengan fokus kepada pengalaman ruang oleh user/ pengguna di dalam bangunan.

c. Fokus terhadap pendekatan dengan subjek pengguna primer yakni generasi millennial dan menciptakan fasilitas yang tidak membosankan.

d. Menghadirkan desain yang dapat memberikan pengalaman dengan fleksibilitas yang tinggi sehingga ragam fasilitas yang terbentuk secara variatif.

e. Melakukan studi kasus terhadap bentuk proyek sejenis baik dari segi sistem bangunan, material, alat-alat lain yang menunjang bangunan dan lain sebagainya.

\section{DISKUSI DAN HASIL}

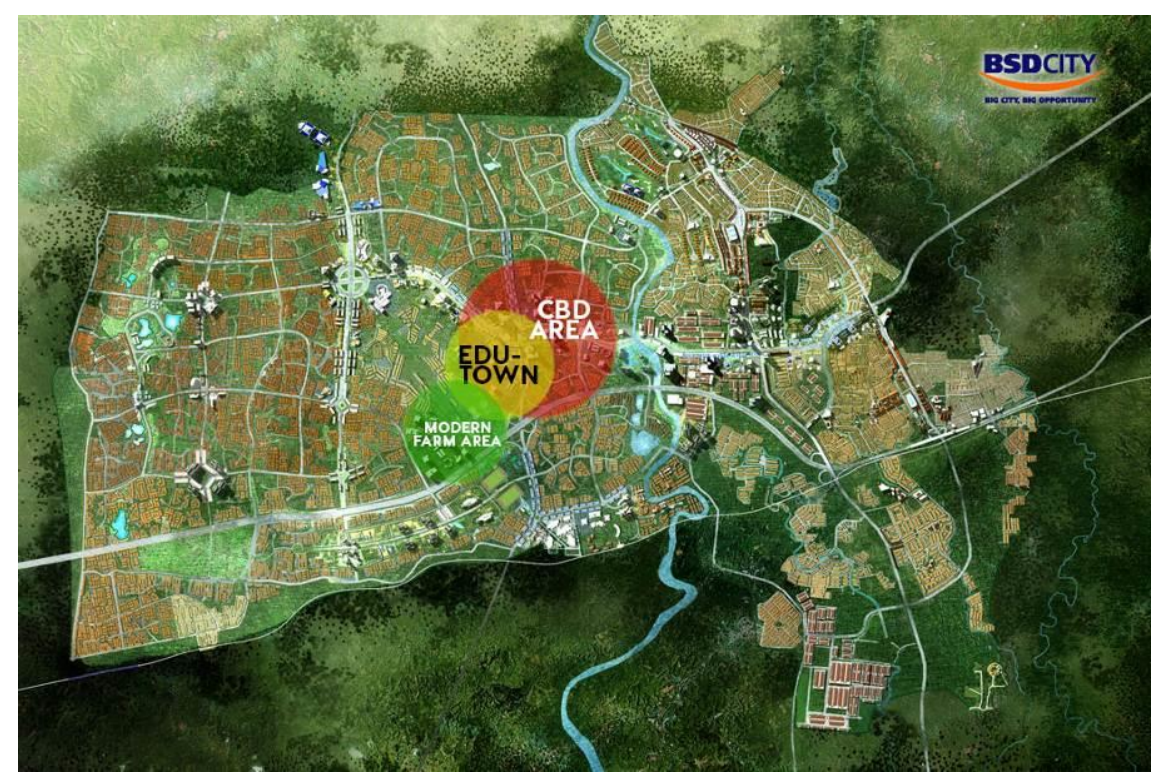

Gambar 1. Rencana Pengembangan Kawasan BSD

Sumber: maps.google.com

Tapak berada di kawasan Edu-Town, BSD. Bumi Serpong Damai atau yang dikenal dengan BSD merupakan kota satelit yang berada di sisi Barat Jakarta yang ditujukan untuk menjadi kota mandiri, dimana seluruh fasilitas akan dihadirkan dalam kota ini termasuk kawasan industri, perkantoran, perdagangan, pendidikan, wisata dan juga perumahan. Kawasan EduTown BSD didukung oleh hadirnya sekolah dan universitas dengan kualitas internasional, hingga saat ini terhitung sudah lebih dari 70 lembaga pendidikan formal hadir di BSD. Kawasan Edu-Town kini menjadi sebuah kawasan edukasi yang terintegrasi, yang mengintegrasikan gedung-gedung universitas dan sekolah berstandar internasional dengan asrama, hunian/ apartemen, pusat perbelanjaan dan taman. Kawasan ini memberikan nuansa pendidikan dengan lingkungan yang hijau dan modern guna mendorong kreativitas, inovasi dan pendekatan yang memacu semangat belajar. Serta kawasan ini dipersiapkan sebagai pusat pendidikan dan proyek penelitian serta riset ilmiah. Dengan visi-misi dan rencana 
pengembangan kedepan yaitu dengan hadirnya CBD (Central Business District), Science Center dan Perpustakaan, diharapkan kedepannya Indonesia memiliki manusia yang memiliki kualitas dan nilai yang mampu menyumbang gagasan dan inovasi kreatifnya demi kemajuan bangsa hingga mampu bersaing di pasar internasional. Kawasan ini dipilih dengan pertimbangan visimisi kawasan yaitu untuk memberikan kemajuan bagi dunia pendidikan Indonesia baik secara formal maupun non formal. Serta dengan adanya dukungan dari berbagai fasilitas yang sudah tersedia, dan mempunyai akses serta infrastruktur yang nyaman dan mudah bagi pengunjung.

\section{Mapping Kawasan Edu-Town}

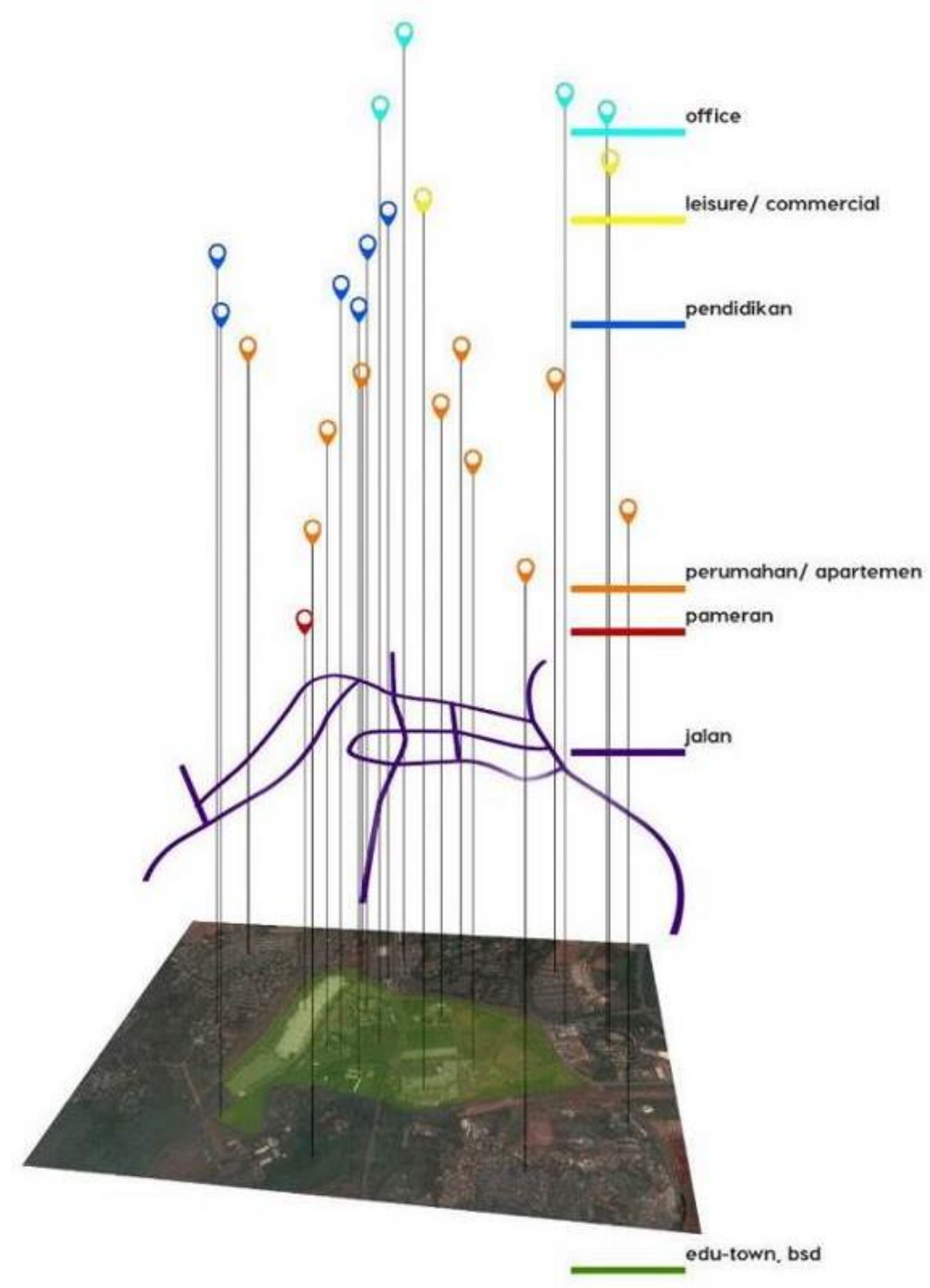

Gambar 2. Analisa Makro Kawasan

Sumber: Penulis, 2019

Melalui gambar di atas dapat dilihat lebih detail mengenai fasilitas-fasilitas yang terdapat di kawasan sekitar Edu-Town BSD dan titik akses/ jaringan jalan di kawasan tersebut. Melalui analisa mapping yang telah dilakukan maka dapat disimpulkan bahwa kawasan ini cocok untuk ditempati oleh Pusat Integrasi Pertanian, karena dengan adanya fasilitas pendukung yaitu institusi pendidikan, perumahan, perkantoran, dan juga komerial. Serta terdapat Balai Besar Pengembangan Mekanisasi Pertanian beserta lahan pertanian menjadi alasan utama penempatan bangunan di kawasan tersebut. 


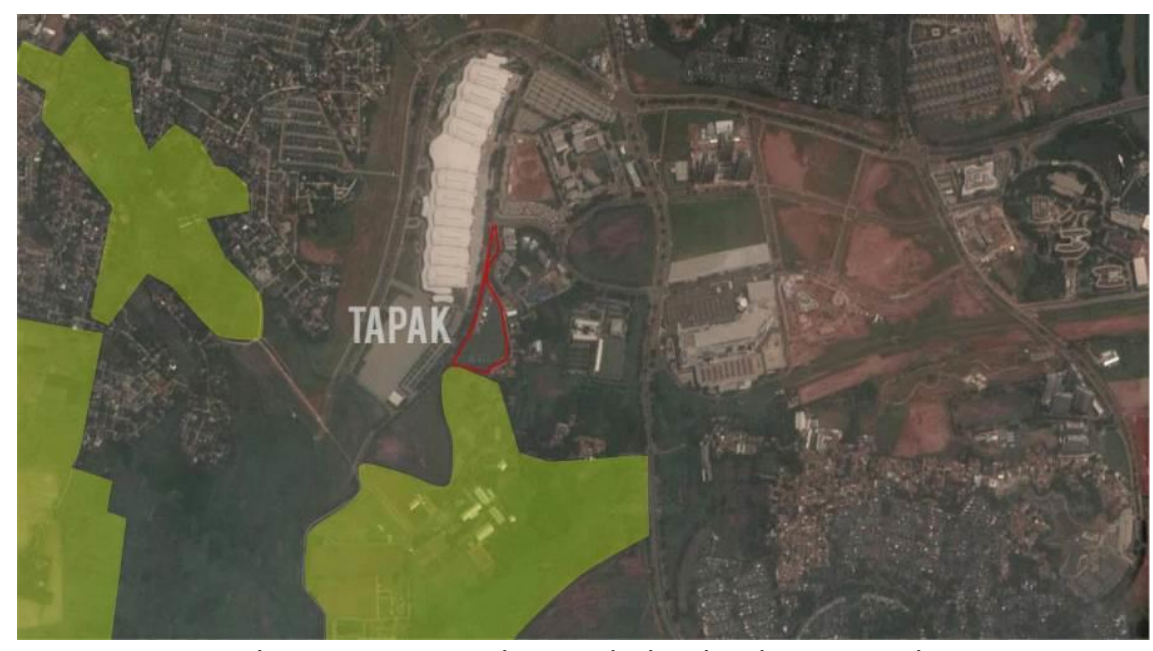

Gambar 3. Citra satelit tapak dan lingkungan sekitar

Sumber: maps.google.com

Lokasi Tapak : Jalan Edu-Town, Tangerang, Banten

Luas Tapak : $24.036 \mathrm{~m} 2$

Peraturan :

- KDB $\quad: 60 \%$

- KLB $\quad: 1.2$

- KD : : $30 \%$

- Menyediakan lahan parkir dan RTH minimal 10\% dari luas lahan

Batas Wilayah :

- Batas Utara : Jalan, Universitas Prasetya Mulya, STEM Enjiniring

- Batas Barat : Jalan, ICE BSD

- Batas Timur : Jalan, Dormitory, B Residence, STABN Sriwijaya, Edutown

- Batas Selatan : Lahan Pertanian, Balai Besar Pengembangan Mekanisasi Pertanian

\section{Analisa Fungsi dan Ruang}

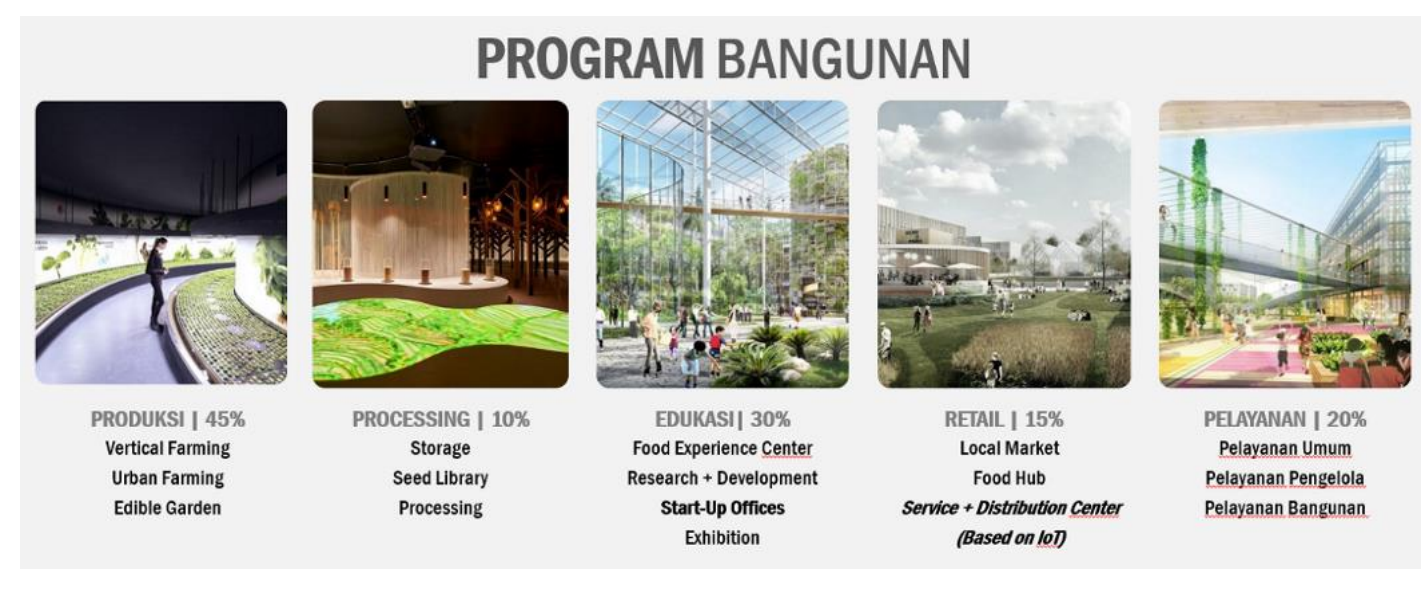

Gambar 4. Program Bangunan

Sumber: Penulis, 2019

Pusat Integrasi Agrikultur terbagi menjadi 3 massa yakni Market, Food Experience Center, dan Research + Office dengan 5 fungsi utama yaitu produksi, processing, edukasi, retail dan pelayanan. Semua fungsi ini saling berkaitan satu sama lain untuk mewadahi user dalam bangunan. Fungsi produksi untuk menghasilkan produk-produk agrikultur yang secara 
penempatan dibagi menjadi secara horizontal dan vertikal, pada horizontal digabung menjadi lansekap bangunan serta menjadi showcase dari produk tersebut bagi pengunjung yang mengunjungi bangunan ini. Secara vertical masuk ke dalam pertanian vertikal yang selain sebagai tempat produksi juga ditujukan untuk riset dan pengembangan. Pada massa yang berfungsi sebagai market terdapat fungsi retail dan processing untuk pelayanan dan juga memenuhi kebutuhan pasar juga menjadi nilai komersil pada bangunan ini. Pada massa food experience center tersedia workshop-workshop untuk merasakan pengalaman proses dari dunia agrikultur, karena bagi generasi milenial pengalaman dan eksplorasi merupakan hal yang paling penting. Sehingga kesemua massa dan lansekap bangunan berkaitan satu sama lain agar pengguna/ pengunjung yang mengunjungi bangunan ini dapat merasakan pengalaman agrikultur secara maksimal dan juga mengefisiensi proses agrikultur ke dalam sebuah tapak/ lahan.

\section{Analisa Tapak}

Analisa tapak merupakan analisa yang bertujuan untuk mengidentifikasi semua faktorfaktor yang mepengaruhi bangunan dalam suatu tapak yang kemudian faktor-faktor tersebut dievaluasi dampak positif dan negatifnya. Melalui identifikasi dan evaluasi tersebut akan menghasilkan solusi dalam merencanakan tapak.

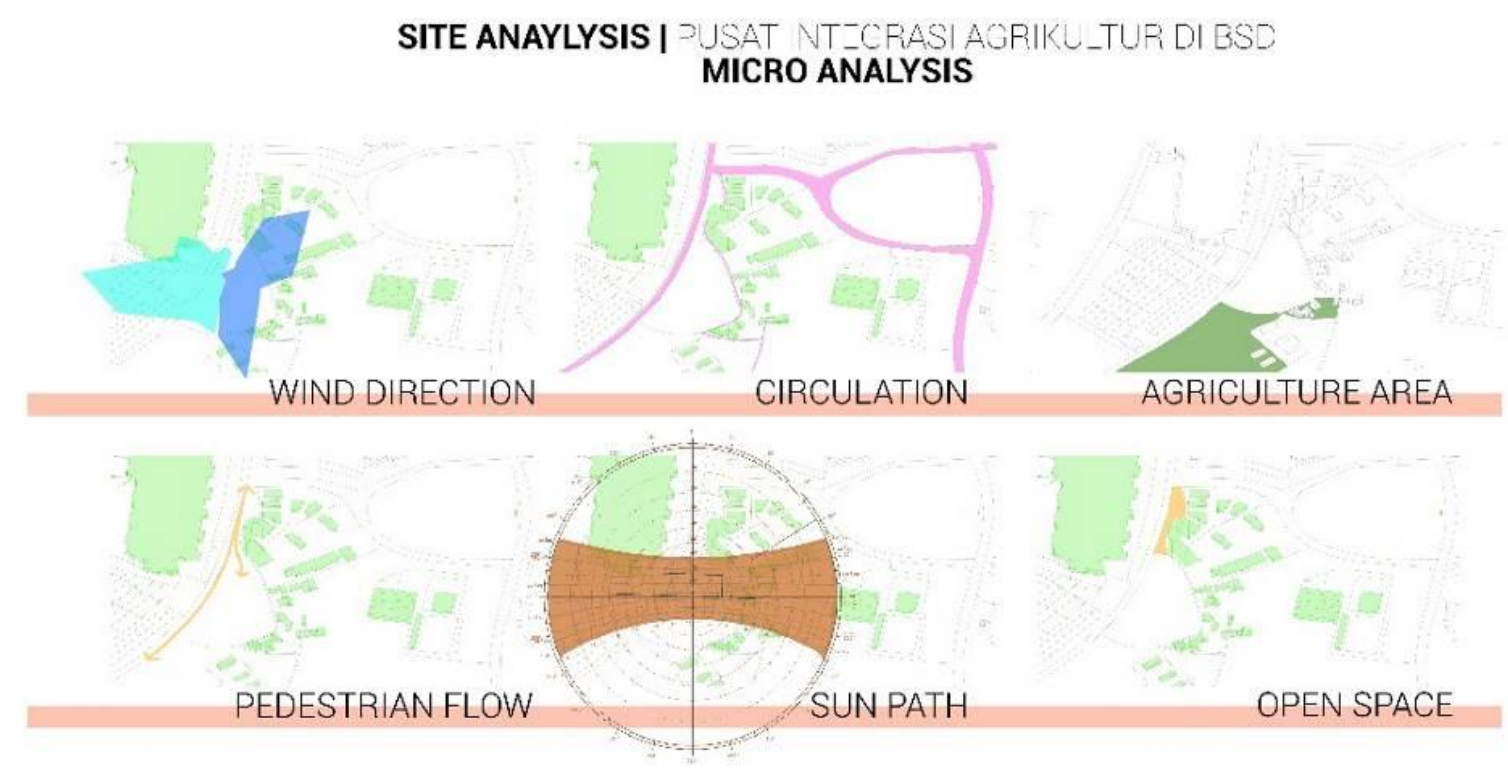

Gambar 5. Analisa Mikro

Sumber: Penulis, 2019

\section{Pencapaian dan Sirkulasi dalam Bangunan}

Pencapaian untuk menuju site ini dapat melalui non kendaraan ataupun kendarana baik kendaraan pribadi dan juga transportasi publik yang tersedia di seberang tapak. Sirkulasi dalam tapak juga dipisah menjadi 2 yaitu zona kendaraan dan zona non kendaraan dengan orientasi memaksimalkan desain bagi pedestrian agar dapat leluasa bergerak di dalam bangunan dan penempatan zona non kendaraan dibagi menjadi 2 titik yaitu untuk drop off (parkir) dan loading dock.

Iklim

Menanggapi iklim respon desain bangunan adalah dengan massa majemuk agar menghasilkan pencahayaan dan pengudaraan alami secara maksimal. Didukung dengan inner courtyard dan ruang void pada dan antar massa bangunan yang diolah sesuai dengan fungsi dan program bangunan. Orientasi bangunan ke utara dan selatan sebagai respon dan 
memberikan ruang masuk bagi cahaya dan menangkap sinar untuk penerangan di dalam bangunan. Arah orientasi view keluar dan ke dalam bangunan dengan menciptakan inner courtyard sehingga view lebih banyak variasi dan dapat dilihat dari arah manapun. Sedangkan view keluar difungsikan sebagai orientasi terhadap lingkungan sekitar.

\section{MASTERPLAN FRAMEWORK}

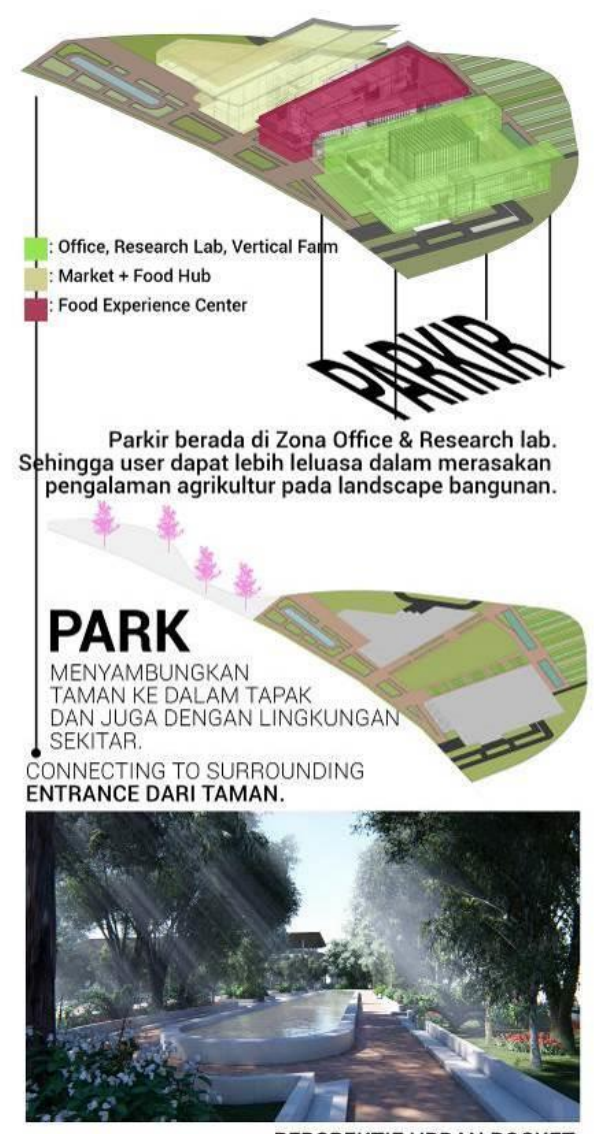

\section{KONSEP PEMBENTUKAN MASSA}
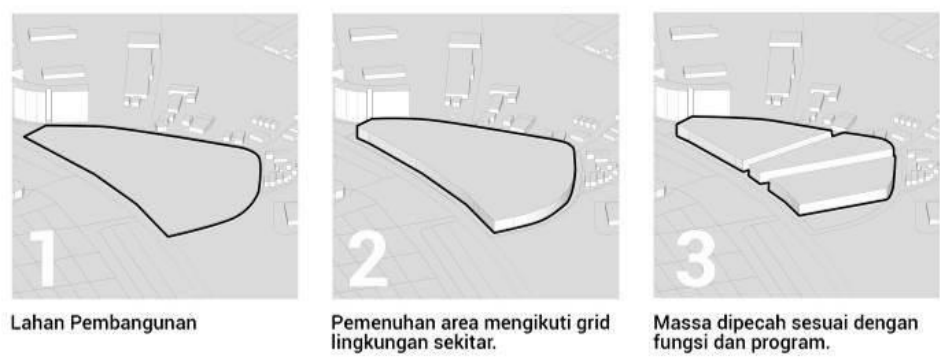
fungsi dan program.
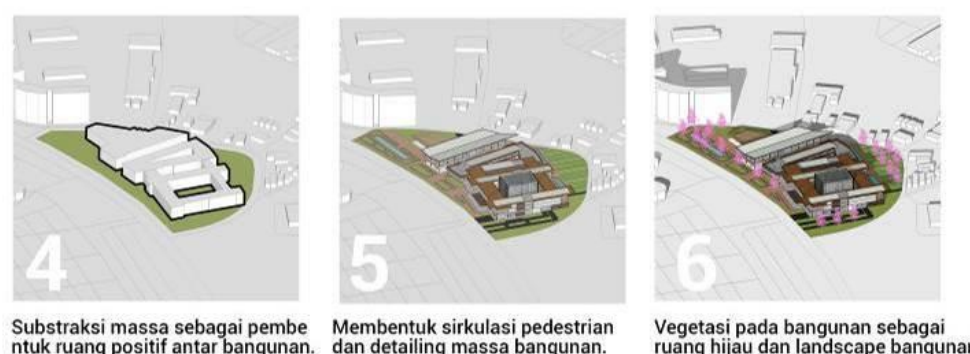
Substraksi massa sebagai pembe Membentuk sirkulasi pedestrian
ntuk ruang positif antar bangunan. dan detailing massa bangunan.
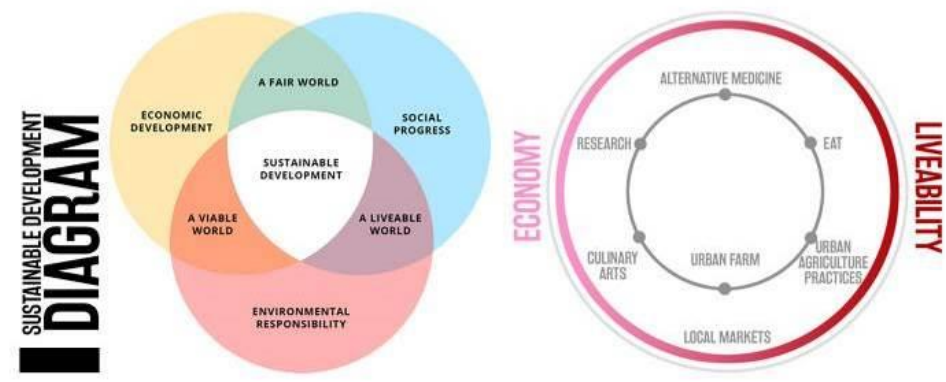

Gambar 6. Konsep Perancangan

Sumber: Penulis, 2019

\section{Zonasi Tapak dan Tata Massa}

Zonasi tapak dibagi menjadi 3 bagian, dengan area komersial yang dekat dengan zona perumahan di lingkungan sekitar serta berdasarkan footprint kegiatan dari tapak yang sudah ada sebelumnya. Zona tengah merupakan food experience center sebagai penghubung dan sesuai dengan program yang ditujukan untuk merasakan nuansa dan menikmati pengalaman proses agrikultur. Zona terakhir yaitu research + office yang membutuhkan konsentrasi sehingga dipisahkan dengan zona komersial secara horizontal yang memiliki aktivitas yang lebih padat sehingga user dalam zona research + office dapat lebih berkonsentrasi dan langsung berhubungan dengan vertical farming sebagai produksi dan juga pengembangan dalam produk dunia agrikultur.

Ruang luar dimanfaatkan sebagai showcase dari produk-produk agrikultur yang ditujukan agar pengunjung dapat merasakan nuansa 'alam' dengan mempadatkan zona ruang dengan vegetasi dan membentuk ruang-ruang public bagi pengunjung. Juga terdapat kolam dan elemen-elemen hardscape dalam pembentukan ruang luar ini. 


\section{Utilitas dan Struktur \\ AKSONOMETRI MEP}
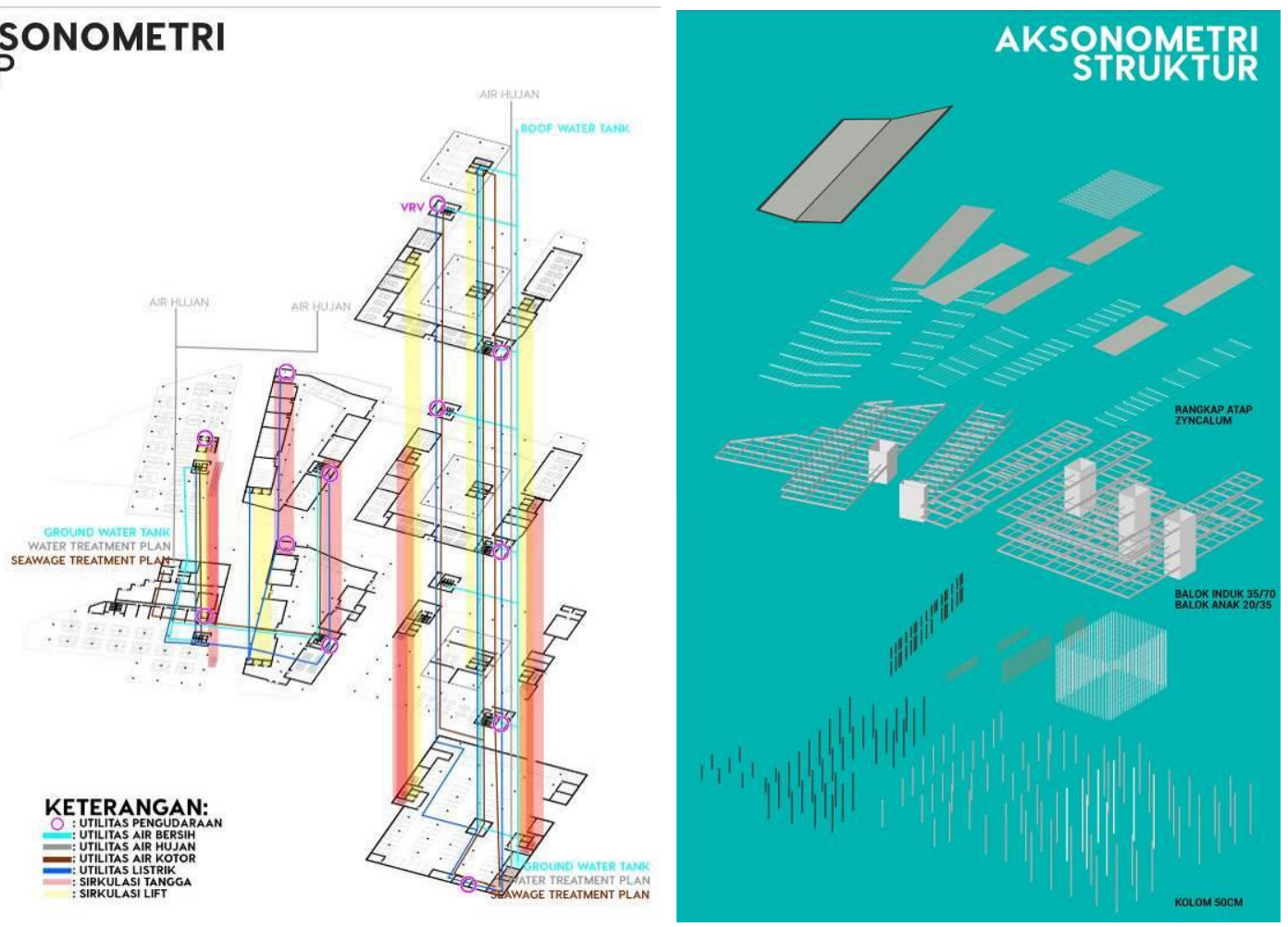

Gambar 7. Diagram Aksonometri MEP (Kiri) dan Aksonometri Struktur (Kanan) Sumber: Penulis, 2019

\section{Konsep, Hasil dan Pembahasan}

Konsep ide desain dari proyek ini berawal dari permasalahan yang mendasar yaitu bagaimana cara menarik minat generasi milenial ke agrikultur dan menghubungkan konteks urban dan konteks pertanian serta menjadi wadah dari sistem pertanian yang terbaru di lingkup perkotaan. Cara yang efektif adalah dengan memberikan pengalaman langsung kepada pengunjung mengenai dunia agrikultur melalui pengalaman/ aktivitas yang bersentuhan langsung dan dapat mereka lakukan. Dalam menjembatani hal ini dilakukan perencanaan melalui lansekap yang dapat dimanfaatkan untuk kegiatan tersebut sehingga suasana di ruang luar juga dapat lebih dinamis dan aktif akibat dari aktivitas-aktivitas yang muncul baik akibat dari pelatihan tersebut atau aktivitas-aktivitas dari program yang sudah dicanangkan pada proyek ini.

Memberikan keseimbangan antara kawasan urban yaitu CBD yang memiliki nilai komersial dan pertanian yang ekologis. Menjadi wadah bagi pengguna di dalamnya melalui programprogram serta menganalisa rekam jejak dari tapak dan juga lingkungan sekitar agar menjadi sistem yang berkesinambungan. Selain itu mengkoneksikan tapak ke lingkungan sekitar memberikan ruang dengan porsi yang lebih banyak kepada pedestrian agar nyaman bersirkulasi di dalam bangunan yang disesuaikan dengan konsep desain. 


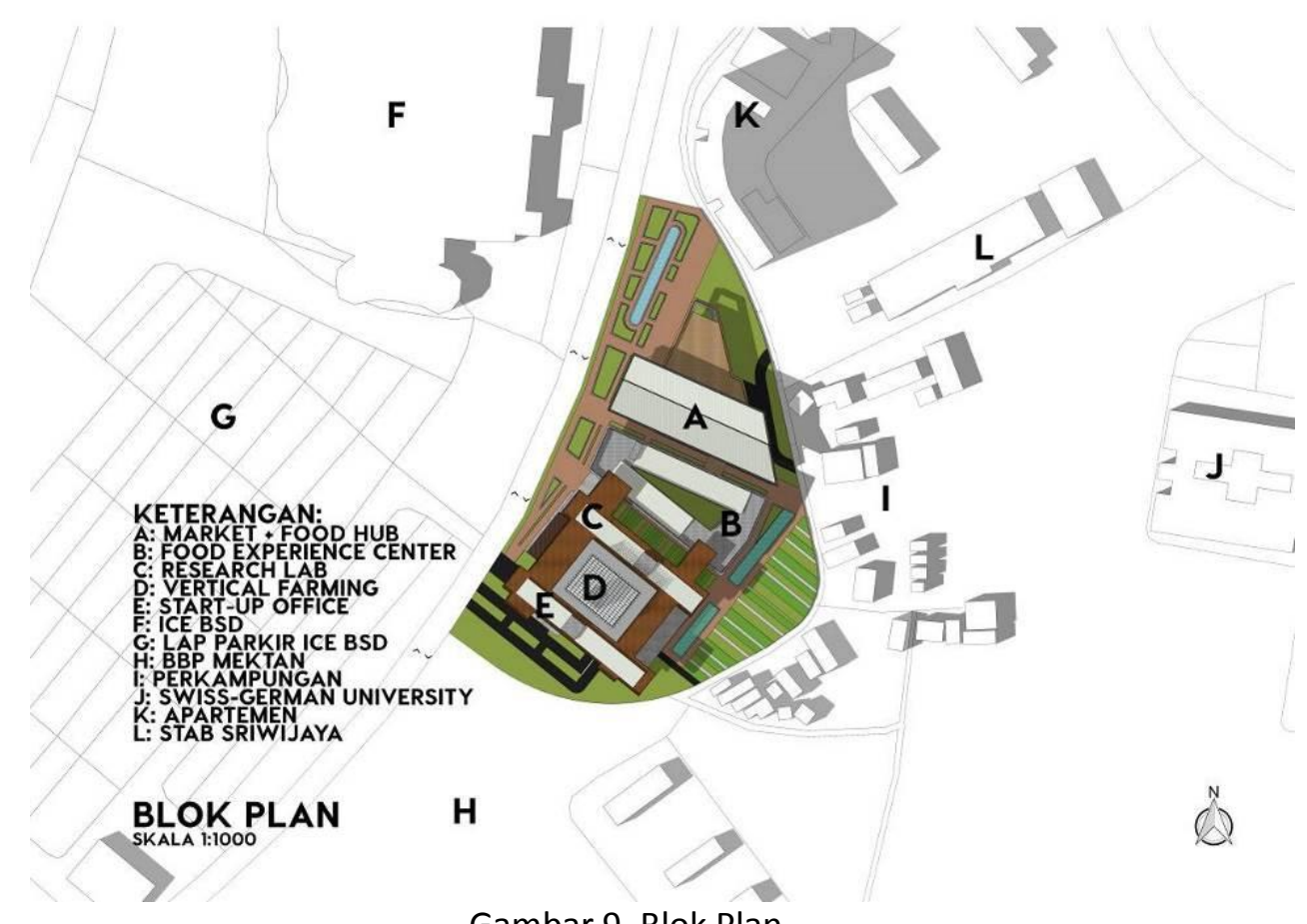

Gambar 9. Blok Plan

Sumber: Penulis, 2019

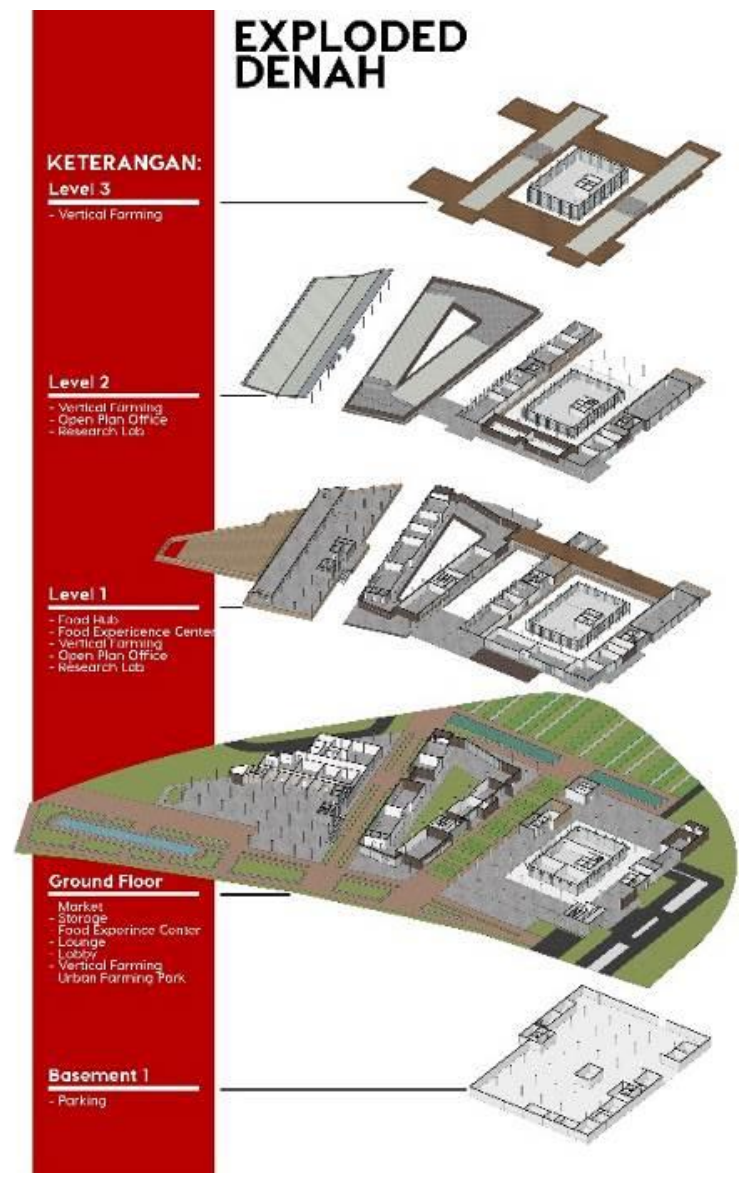

Gambar 10. Eksploded Denah

Sumber: Penulis, 2019 


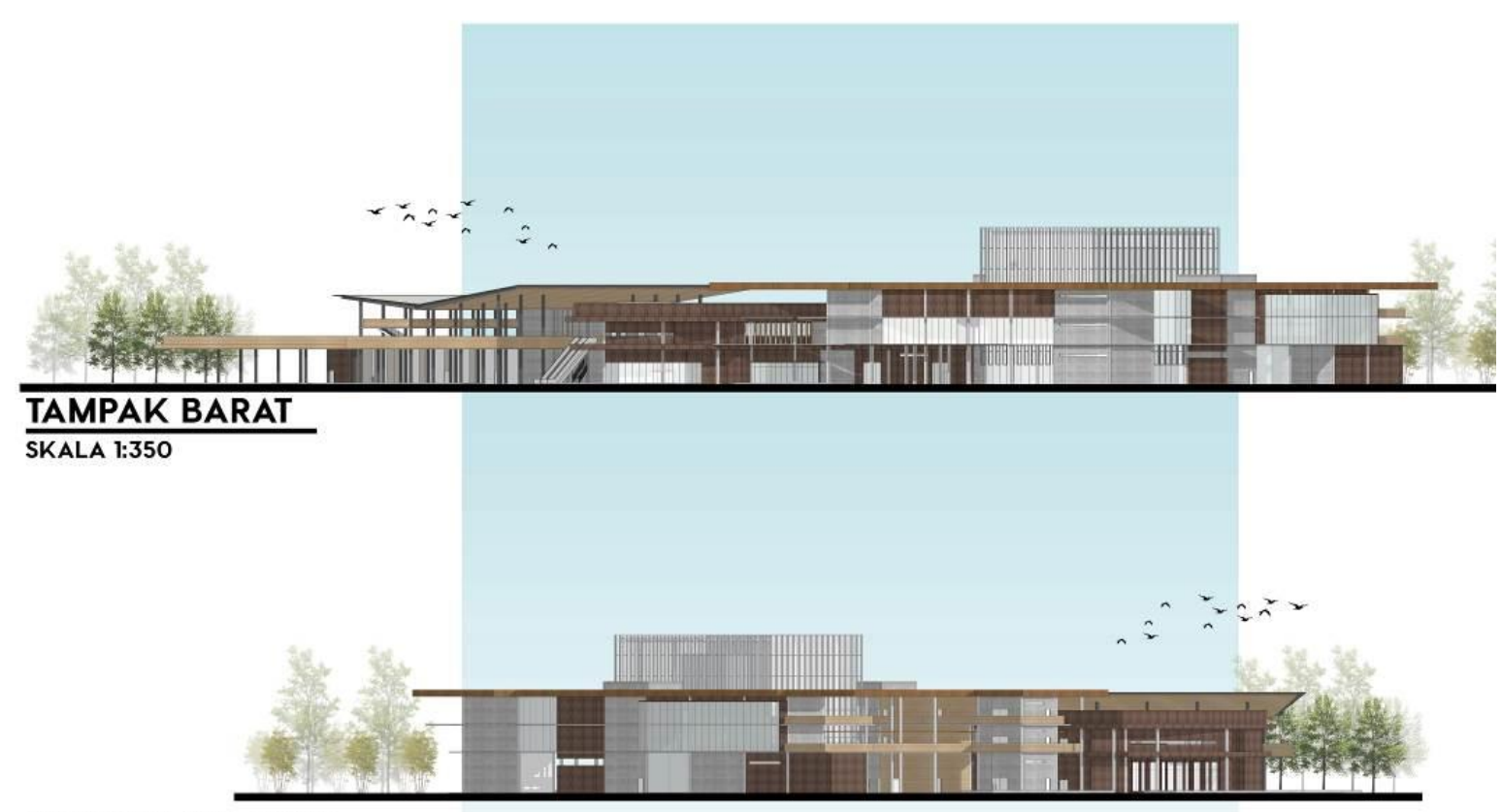

TAMPAK SELATAN

SKALA 1:350

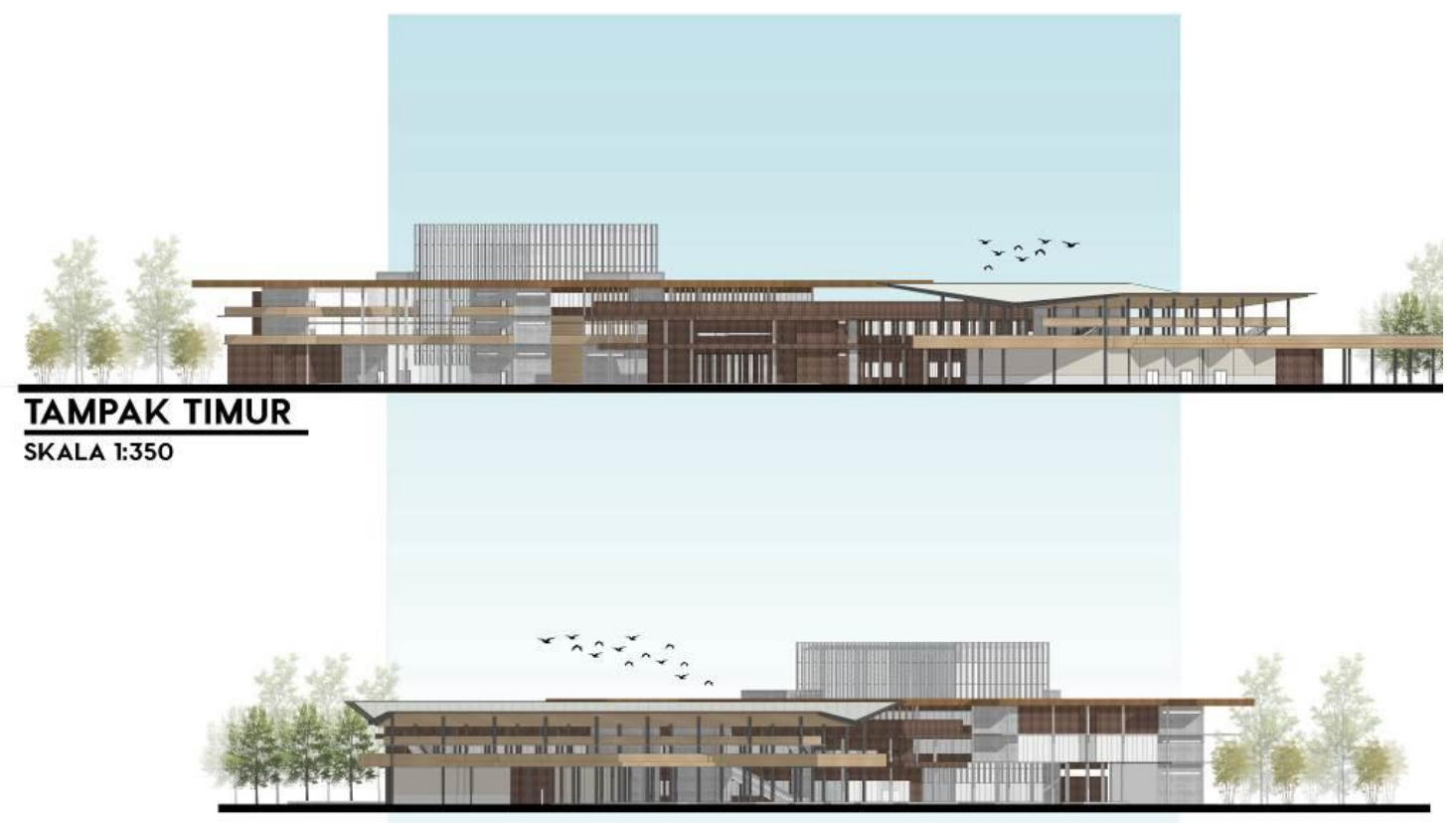

TAMPAK UTARA

SKALA 1:350

Gambar 12. Tampak Bangunan

Sumber: Penulis, 2019 

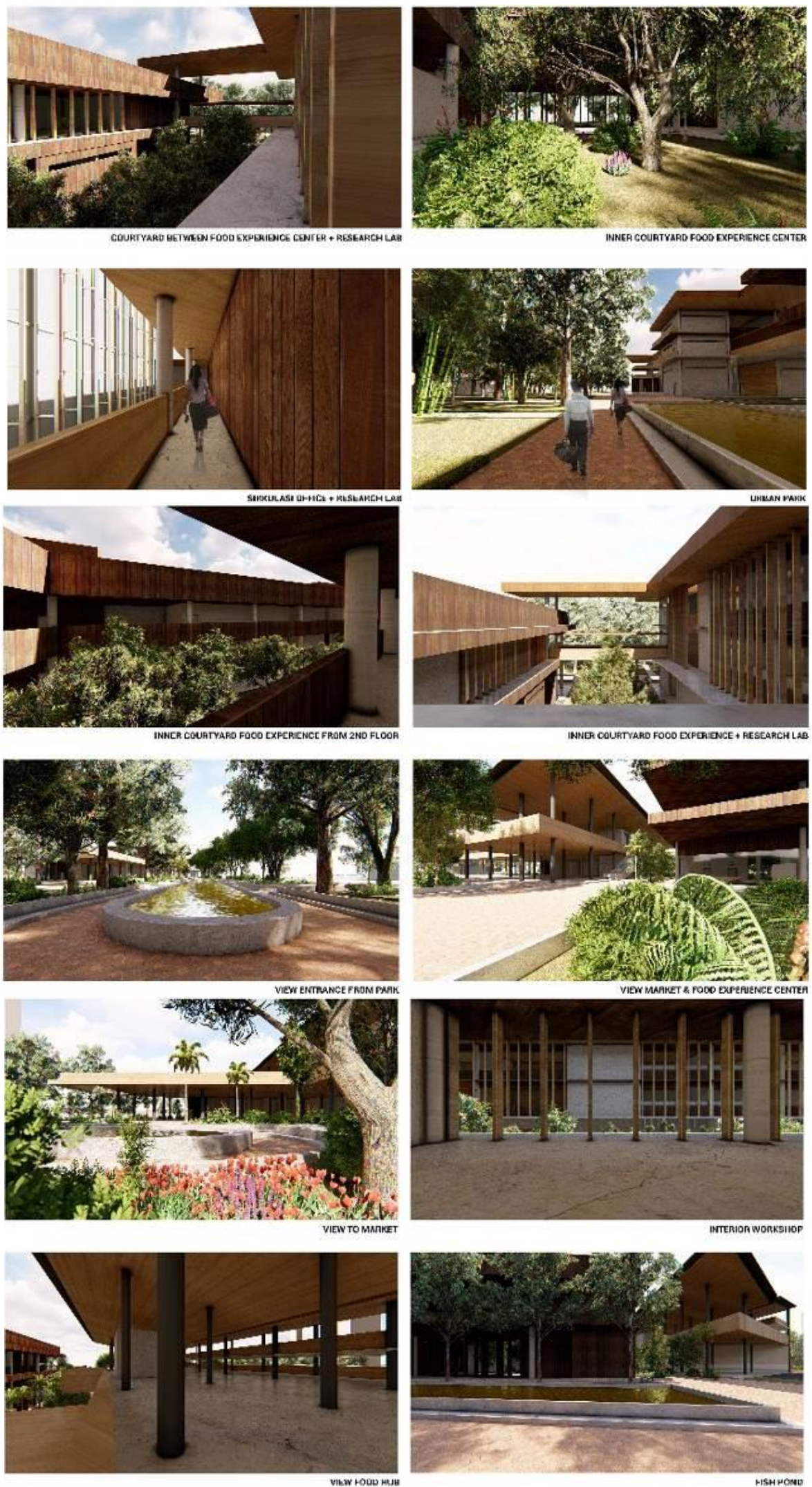

Gambar 15. Perspektif

Sumber: Penulis, 2019 


\section{KESIMPULAN DAN SARAN}

Proyek "Pusat Integrasi Agrikultur di BSD" ini bertujuan untuk mengkoneksikan lahan pertanian seluas 200 ha yang terbesar di sekitar kawasan dengan lingkungan perkotaan, mendukung rencana pembentukkan kawasan pertanian modern di BSD dan dapat mewadahi segala proses yang terjadi dalam penghasilan produk pangan hingga penjualan di dalam sebuah tempat untuk meningkatkan kualitas pertanian lokal dan mengedukasi masyarakat mengenai pertanian sehingga nantinya diharapkan pertanian dapat melebur dalam konteks urban yang lebih luas. Penggabungan program ruang pertanian dengan fungsi kota pada desain bangunan dapat mendukung dan meningkatkan kualitas urban life pada kehidupan kota dan memberikan nuansa hijau pada kota tersebut. Serta program-program ini dapat mencegah penurunan ketertarikan terhadap profesi pertanian, karena sekarang bertani dapat dilakukan dimanapun. Melalui program ini juga dapat menghasilkan siklus pertanian yang lebih sustainable bagi petani lokal sehingga dapat menjadi lebih efisien dan maksimal dalam prosesnya.

\section{REFERENSI}

Food and Agriculture Organization of the United Nations. (2015). Cities of despair - or opportunity?. United Nation

Gede M. (2017). Pengantar Ilmu Pertanian [Electronic Version]. Bali: Universitas Udayana

Hart, C. (1998). Doing a literature review: Releasing the social science research imagination. Sage.

Hawkins, D. I. dan Mothersbaugh, D.L. (2010). Consumer behavior : Building marketing strategy. New York: McGraw-Hill.

J.B. Penn, Ronald D. Knutson, dan Barry L. Flinchbaugh. (2006). Agricultural and Food Policy. New-Jersey: Prentice Hall PTR

Kementrian Perindustrian. (2018). Making Indonesia 4.0. Jakarta: Kementrian Perindustrian.

Kemenperin. (2018). Making Indonesia 4.0: Strategi RI Masuki Revolusi Industri Ke-4. Retrieved January 14, 2019, from http://www.kemenperin.go.id/artikel/18967/Making-Indonesia-4.0:-Strategi- $\quad$ RIMasuki Revolusi-Industri-Ke-4

Latif D., A. (2017). The World Could Run Out of Food Two Decades Earlier Than Thought. Retrieved February 2, 2019, from https://qz.com/africa/1064653/the-world-couldrun-out-of-food-twodecades-earlier-than-thought/

Manguiat IJ. (1995). In Search of Alternative Fertilizers for Sustainable Agriculture: The Sestania Option. Philippines: SEAMEO-SEARCA, Los Banos.

Ningrum V. (2017). Krisis Pangan Ancam Indonesia. Retrieved February 5, 2019, from http://lipi.go.id/lipimedia/krisispangan-ancam-indonesia/19061

Piesse, M. (2016). Food Security in Indonesia a Continued Reliance on Foreign Markets. Retrieved February 5, 2019, from http://www.futuredirections.org.au/publication/food-security-in-indonesiaacontinued-reliance-on-foreign-markets/

Rosari, A. (2017). Bonus Demografi dan Dampak Terhadap Indonesia. Retrieved January 19, 2019, from

https://www.kompasiana.com/andhinirosari/5a2e2c4acf01b4574160ed32/bonusdemografi-dan-dampak-terhadap-indonesia?page=all

Ruaf. Urban Agriculture: What and Why ?. Retrieved January 20, 2019, from https://www.ruaf.org/urbanagriculture-what-and-why

Sinarmasland. Tentang BSD City. Retrieved January 10, 2019 http://bsdcity.com/thecity/about-bsd-city

Soekartawi. (1995). Analisis Usaha Tani. Jakarta : UI Press. 
Solomon, M.R. (2009). Consumer behavior : Buying, having, and being. New Jersey : Pearson Education Inc.

Sweeney, R. (2006). Millennial Behaviors \& Demographics. New Jersey Institute of Technology

Utomo, P. W. (2019). Indonesia Millennial Report 2019 [Electronic Version]. Jakarta: IDN Research Institute

United Nation. (2016). About the Sustainable Development Goals. Retrieved January 22, 2019, from https://www.un.org/sustainabledevelopment/sustainable-developmentgoals/ 